\title{
O Estudo Psicossocial Forense como Subsídio para a Decisão Judicial na Situação de Abuso Sexual
}

\author{
Ivonete Araújo Carvalho Lima Granjeiro ${ }^{1}$ \\ Universidade Católica de Brasília \\ Liana Fortunato Costa \\ Universidade de Brasília
}

\begin{abstract}
RESUMO - Esta pesquisa teve como objetivo aprofundar os conhecimentos na interface Psicologia/Direito, envolvendo uma situação de violência intrafamiliar. Buscou-se conhecer as reflexões dos vários atores que participaram das decisões referentes a um processo sobre abuso sexual cometido pelo pai contra duas filhas crianças. O contexto foi uma Vara Criminal e o método o de estudo de caso. A análise dos resultados seguiu a orientação da Hermenêutica de Profundidade. Os resultados foram discutidos segundo três eixos de compreensão da função do estudo psicossocial forense: A quem serve? Quando deve ser realizado? E o que subsidia o processo judicial: o laudo ou o relatório? Concluímos que é necessário promover a interação entre os vários atores que complementam suas decisões, para que se possa ampliar a compreensão da realidade que cerca as situações de violência na família, e assim o contexto judicial participar na promoção da cidadania nesses casos.
\end{abstract}

Palavras-chave: psicologia clínica; psicologia jurídica; abuso sexual; estudo psicossocial forense.

\section{The Forensic Psychosocial Study as a Subsidy for the Juridical Decision in the Situation of Sexual Abuse}

\begin{abstract}
This research aimed at deepen knowledge in the Psychology/Law interface, involving an intrafamiliar violence situation. We tried to know the way of thinking of the various actors who participated in the decisions related to a process of sexual abuse committed by a father against two daughters. The context was a criminal court and the method was the case study. The analysis of the results followed the guidelines of the In-Depth Hermeneutics. The results were discussed in accordance with three sets of comprehension of the forensic psychosocial study function: To whom it serves? , When it must be made? And what subsidizes the judicial process: the evaluation report or the study? We came to the conclusion that it is necessary to promote the interaction among the various actors who complement their decisions in order to increase the comprehension of the reality surrounding the situations of familiar violence so that the judicial context may participate in the promotion of citizenship in these cases.
\end{abstract}

Key words: psychology; clinical psychology; forensic psychology; sexual abuse; forensic psychosocial study.

Procuramos, neste texto, discutir as possibilidades de uma ação concertada entre a Psicologia e o Direito, envolvendo uma situação de violência intrafamiliar, mais especificamente de abuso sexual infantil, a par de subsidiar decisões judiciais mais adequadas à realidade da família, por meio de um objeto específico que é o estudo psicossocial forense. A pesquisa original, na qual o texto se baseia, teve como escopo uma análise qualitativa das ações dos profissionais do Direito e da Psicologia que utilizam o estudo psicossocial forense para complementarem suas argumentações em processos judiciais. O estudo psicosocial forense é elaborado pelos técnicos do Setor Psicossocial, e indicamos a definição de Lima (2003), que o aponta como um estudo realizado por psicólogos e assistentes sociais de um Tribunal de Justiça, e que "assessoram nas decisões dos magistrados em questões referentes às famílias procurando promover pequenas intervenções no sistema atendido" (p. 16).

Buscamos conhecer como esses profissionais percebem a importância desse estudo e ampliar uma discussão sobre

1 Endereço: SHIS QL 10, conjunto 09, casa 07 - Lago Sul Brasília, DF, Brasil 71630-095.E-mail: ivonety@terra.com.br a compreensão complementar das perspectivas jurídica e psicológica. Pretendemos, ainda, colaborar no sentido de discutir uma interdisciplinaridade entre a Psicologia e o Direito, com o intuito de garantir um espaço relacional que proporcione mudanças no universo comunicativo de interação entre os juízes, promotores, defensores e os psicólogos e assistentes sociais de um Setor Psicossocial Forense. Um efetivo diálogo entre essas duas áreas de conhecimento, bem como uma análise reflexiva da importância da interdisciplinaridade como instrumento, pode possibilitar a diminuição da violência intrafamiliar e a promoção da Justiça. A interação dessas ciências tornará mais efetivas as decisões judiciais, uma vez que os trabalhadores do Direito e da Psicologia serão co-autores em ações conjuntas, a fim de conciliar a aplicação da lei com as reais necessidades da família.

\section{Direito, Família e Violência}

No que concerne à proteção da família, incluindo a criança, o adolescente e o idoso, o constituinte de 1988 - cauteloso - criou um capítulo específico: "Da Família, da Criança, do Adolescente e do Idoso". Nesse capítulo, o legislador fez 
constar normas de efetividade imediata como, por exemplo, o $\$ 5^{\circ}$ do art. 226, que garante a igualdade entre o homem e a mulher na condução da sociedade conjugal. Fez constar, também, normas programáticas, que são, segundo Silva (2000), normas que não regulam de modo direto e imediato determinadas situações e relações; têm como mister estabelecer aquilo que os governantes deverão ou poderão fazer, sem criar uma obrigação de fazer ou um prazo estabelecido para praticar essas ações. Assim, essas normas dependem de ações do Estado para se tornarem efetivas. Esse é o caso do $\S 8$ o do art. 226 da Constituição Federal, in verbis: “O Estado assegurará a assistência à família na pessoa de cada um dos que a integram, criando mecanismos para coibir a violência no âmbito de suas relações".

O paradigma da positivação das normas e a separação do Direito de qualquer outra área de conhecimento, com os pressupostos da racionalidade, da simplicidade, da estabilidade e da objetividade, ratificados pela ciência chamada moderna, que apresentou como um dos seus objetivos a separação das "ciências físicas de humanas, de sociais; de separar física de química, de psicologia, de sociologia, de biologia" (Vasconcellos, 2002, p. 8), torna inexeqüíveis a Constituição e os tratados de direitos humanos de que o Brasil é signatário. O fenômeno jurídico isolou-se dos fenômenos econômicos, psicológicos, educacionais, entre outros. Como consequiência, a produção do conhecimento jurídico-científico buscou - essencialmente - ordenar e controlar a realidade social. Dessa forma, todos os princípios de explicação do fenômeno jurídico passaram por um pensamento de simplificação, no qual a aparente complexidade das coisas pudesse ser explicada por meio de procedimentos de separação e redução dos fenômenos (Morin, 1990)

O juiz, ao se deparar com um processo, considerado como fato jurídico, deve buscar seu elemento explicativo na lei, separando-o e isolando-o dos outros fatos sociais, na medida em que a objetividade, a racionalidade e a imparcialidade devem nortear o seu mister de julgar, sem interferência de qualquer elemento externo ao processo, pois o positivismo a que ele está subordinado determina a hierarquização, a unificação e a generalização de tudo que parece diferente, a fim de estabelecer um controle dos fenômenos. No entanto, a complexidade dos fenômenos apresentados, especialmente nas varas de família e nas varas criminais, tem demandado - para a sua compreensão - uma postura diferente dos profissionais do Direito. A criação de contextos mais integrados de conhecimento e ação - nos quais as pessoas no processo possam assumir "a competência da autoria de suas próprias vidas" (Vasconcellos, 2002, p. 9) -, que privilegiam, ao mesmo tempo, a aplicação da lei de forma que atenda a diversidade, a unicidade, o sujeito e o seu contexto, e a articulação com outros saberes tornará a lei exequiível, ou seja, o plano abstrato será aplicado com eficiência no plano concreto.

A discussão da ineficácia das leis, perante uma realidade social em constante mudança, tem propiciado um espaço de crise e de reflexão no meio jurídico, principalmente no que respeita às decisões judiciais. Os juristas mais comprometidos com uma justiça emancipatória estão reinventando a sua práxis, pela leitura e releitura das situações cotidianas desenhadas no processo. Esse pensamento, que vai ao encontro de uma perspectiva sistêmica, amparo teórico deste trabalho, e apresenta o processo com uma visão integradora entre o Direito e a Psicologia, procura trocar o pensamento disjuntivo (ou-ou) por um pensamento integrador (e-e), provocando mudanças na ação, ou seja, a ação parte de uma reflexão, de uma análise que se faz das novas informações apresentadas. Vai-se da ação à compreensão e da compreensão à ação, até a síntese, que é a interação entre os elementos e não nos elementos em si. Essa atitude faz com que todo conhecimento, inclusive o jurídico, seja revisado, não havendo nenhum conhecimento definitivo, incontestável, pois o conhecimento, na perspectiva sistêmica, tem caráter inconstante, transformador e relacional.

O "surgimento" da violência doméstica como problema social e jurídico, segundo Soares (1999), é um fenômeno recente, porque nos foros acadêmicos brasileiros sempre se encarou a violência doméstica como um aspecto da experiência privada, individual, separada do fenômeno social. O silêncio acadêmico sobre esse tema foi a pedra de toque para muitos autores, entre eles, Nichols e Schwartz (2007). A perpetuação do silêncio, ainda segundo Soares, pode ter sido provocada pelo conservadorismo, puritanismo, sexismo, patriarcalismo, a par da sacralização da família. Soares (1999) lembra que a transição do espaço privado para o público, para o social (e porque não acrescentar o jurídico, pois o fato jurídico surge do fato social), não é conseqüência, apenas, do rol de direitos e garantias que as mulheres (também as crianças e os adolescentes), legitimamente, tiveram reconhecidos pelo legislador brasileiro ou da luta contra o pacto de silêncio, este imposto pela sociedade patriarcal. Na verdade, a violência doméstica se revelou como fenômeno a ser estudado "à medida que certas ações, atitudes e comportamentos tradicionais iam sendo desnaturalizados e classificados como crimes, violações ou agressões intoleráveis" (Soares, 1999, p. 30). A visibilidade necessária para a violência doméstica desencadeou uma crítica ao modelo de intervenção do Estado, especialmente no campo jurídico, pois questionou a "legalidade/legitimidade natural" de o homem agredir a sua família.

O conhecimento do que se passa nos lares, e que os processos criminais e de varas de famílias revelam, desmistifica a família como lugar de segurança e de acolhimento contra as ameaças da sociedade. Corsi (1999), por exemplo, entende que o espaço familiar é propício para a ocorrência da violência. Ele se opõe às noções idealizadas de que a família é lugar de compreensão, proteção, afeto e segurança. Para esse autor, as características de privacidade, de isolamento e de intimidade provocam interações familiares que tendem a ser conflituosas. $\mathrm{O}$ conflito é inerente à vida em família e isso não significa - necessariamente - que deva desembocar em violência. O que o autor destaca é que a negação da inevitabilidade do conflito contribui para o surgimento e o agravamento da violência.

Segundo o sociólogo português Boaventura de Sousa Santos (2000), o Judiciário transforma a lei em uma promessa vazia. Isso porque as instituições judiciárias, especialmente a magistratura, são incapazes de lidar com os conflitos que lhes são apresentados. Isso é resultado, segundo Sousa Júnior (2002), de uma crise decorrente do esgotamento do paradigma da cultura legalista - a lei resolve tudo - e da própria formação acadêmica, que aliena o jurista e não o afasta das pré-noções ideológicas que moldaram a concepção jurídica 
de mundo, esta insuficiente para dar conta da "complexidade e das mutações das realidades sociais, políticas e morais numa conjuntura de transição paradigmática" (p. 146). Assim, a transformação da violência doméstica em crime não é suficiente para lidar com o problema. É apenas um primeiro passo, que deverá ser acompanhado pela demarcação de um novo perfil para as instituições judiciárias, um perfil voltado para impulsionar a transformação do imaginário dos juízes, torná-los sujeitos criativos e agentes preocupados com a função social da magistratura.

Sobre a importância de uma discussão envolvendo o estudo psicossocial forense, nos reportamos aos vários trabalhos compilados no livro coordenado por Lima (2003), que, nos parece, consegue apontar a compreensão do significado desse estudo e sua inserção nos diferentes tipos de conflitos familiares que chegam aos tribunais para serem decididos. O estudo psicossocial forense é peça fundamental para muitos casos de disputa de guarda, ou de tutela ou de impedimento da criança pernoitar com um dos genitores, ajudando o juiz a decidir com vistas ao melhor interesse da criança. $\mathrm{O}$ campo de conhecimento da Psicologia Jurídica, no Brasil, é recente e ainda apresenta poucos autores publicando e/ou discutindo essa interface entre Psicologia e Direito (Brito, Ayres \& Amendola, 2006; Bucher, 1992; Costa \& Santos, 2004; Costa, Penso \& Almeida, 2005; Penso \& Sudbrack, 2004; Sudbrack, 1992). Consideramos que estamos contribuindo para a ampliação do conhecimento dessa interface ao nos determos em maiores detalhes sobre a utilização desse estudo, já que o campo de interação entre o Direito e a Psicologia necessita de um olhar mais atento para suas particularidades, na construção de uma relação não tão hierarquizada e mais colaborativa, conforme nos mostram Costa, Penso e Almeida (2006).

\section{Método}

Esta pesquisa começou a ser delineada a partir das experiências das pesquisadoras na lide de orientar e encaminhar famílias que sofrem situações de violência sexual e passam pela condição de serem sujeitos de um estudo psicossocial forense. Os questionamentos e as reflexões acerca das leis aplicadas ao caso concreto e a inadequação destas para resolver os conflitos familiares levaram-nos à busca de respostas, para que a prática psicossocial na justiça possa alcançar a realidade tanto emocional como psicológica e contextual dessas famílias.

\section{Estudo de caso}

O método escolhido foi o do estudo de caso. González Rey (2002) afirma que a importância do estudo de caso se encontra na condição qualitativa de singularidade. O estudo de caso gera e produz conhecimentos sobre a subjetividade individual, com a efetiva participação do investigador, este presente em todo o processo de construção do conhecimento.

\section{Contexto}

O contexto de realização da pesquisa foi uma vara criminal de uma cidade de periferia de uma grande capital. Buscouse conhecer as reflexões dos vários atores que participaram das decisões referentes a um processo sobre abuso sexual cometido pelo pai contra duas filhas, uma de 1 ano de idade e outra de 4 anos de idade. Tivemos acesso ao processo, identificamos os atores do judiciário que participaram do processo, fizemos as entrevistas com o objetivo de conhecer suas reflexões acerca de sua participação e significado nas decisões presentes na sentença judicial.

\section{O caso}

O pai constrangeu suas filhas ao permitir que com elas fossem praticados atos libidinosos diversos da conjunção carnal. A mãe das crianças trabalhava como diarista em período integral e, algumas vezes, deixava suas filhas com o pai, que trabalhava esporadicamente como auxiliar de pedreiro. Após as vizinhas alertarem a mãe, esta o denunciou. $\mathrm{O}$ magistrado responsável pelo processo pediu o encaminhamento dos autos ao Setor Psicossocial Forense do Tribunal de Justiça, a fim de que fosse realizado estudo do caso. A conclusão do relatório psicossocial foi que as crianças vivenciaram situações de violência sexual, perpetrada pelo pai, além de serem expostas, durante a união de seus pais, a episódios de alto grau de violência. Em abril de 2005, o juiz da vara proferiu sentença, condenando o pai das crianças a nove anos, cinco meses e 22 dias de reclusão, sendo o regime de cumprimento da pena integralmente fechado. Foi negado o direito de apelar em liberdade.

\section{Participantes}

Os participantes da pesquisa foram: três operadores do Direito (juiz da causa: 45 anos, 10 anos de profissão; a promotora de justiça: 28 anos, um ano e seis meses no cargo; a defensora pública: 28 anos, nove meses na profissão); e duas profissionais da Seção Psicossocial Forense (a psicóloga: 42 anos, 10 anos de profissão; a assistente social: 35 anos, cinco anos de profissão). A pesquisa teve início com a aprovação e o consentimento dados pelo juiz titular da vara criminal em questão, e todos os entrevistados concordaram livremente em participar.

\section{Os instrumentos para a investigação}

As entrevistas foram realizadas em abril de 2005, numa perspectiva qualitativa, que tem por escopo converter-se em um diálogo, num processo de construção de significados, em que há um encontro interpessoal que inclui a subjetividade dos participantes, o que desencadeia uma série de elementos de sentido, sobre os quais - segundo González Rey (2002) - o pesquisador nem sequer havia pensado. As entrevistas foram realizadas nos locais de trabalho, gravadas em fitas de gravador e transcritas, posteriormente, para análise.

Os roteiros das entrevistas foram extensos, por falta de espaço, vamos agora enfocar apenas alguns itens abordados com cada sujeito, que indicam a direção do questionamento. Com o juiz: O que o moveu a pedir o relatório psicossocial? De que forma o relatório o auxilia? Como o senhor integra as informações contidas no relatório com a decisão final proferida no processo? Com a promotora: Sendo importante o relatório do setor psicossocial antes do oferecimento da denúncia, de que forma são integradas as informações contidas 
no relatório com a necessidade de apresentar a denúncia do caso? Com a defensora pública: De que forma o relatório a auxilia? A senhora acha importante uma análise psicossocial do agressor, e até mesmo da vítima, para melhor fundamentar a defesa do agressor? Como a senhora entende a contribuição da psicologia na elaboração da defesa final de um processo? Com as profissionais do setor psicossocial: Como estão sendo aplicadas as informações contidas no relatório? O juiz integra ou junta as informações do processo com o que ele precisa conhecer das famílias? Como o profissional do setor psicossocial se vê diante do processo judicial? Há uma relação de complementariedade/interdisciplinaridade entre o Direito e a Psicologia? Como contribuir para o relacionamento entre essas duas áreas de conhecimento? De forma geral, as perguntas foram elaboradas na busca do olhar de cada um sobre o relatório psicossocial e a sua efetiva integração nos procedimentos dos profissionais do Direito.

\section{Método de análise das informações colhidas}

A Hermenêutica de Profundidade, conhecida como HP, se constitui em um referencial metodológico geral, que tem como enfoque aceitar e levar em consideração as maneiras em que as formas simbólicas são interpretadas pelos sujeitos que constituem o campo-sujeito-objeto. Nessa perspectiva, deve-se conceder um papel central ao processo de interpretação da vida quotidiana, pois o estudo das formas simbólicas é fundamentalmente um problema de compreensão e interpretação. "A hermenêutica da vida quotidiana é um ponto de partida primordial e inevitável do enfoque da HP" (Thompson, 2000, p. 363). A análise se faz em três eixos: o primeiro é a Análise Sócio-Histórica que tem como principal objetivo reconstruir as condições sociais e históricas de produção, circulação e recepção das formas simbólicas, a fim de identificar e descrever as situações espaço-temporais específicas em que as formas simbólicas são produzidas - faladas, narradas, escritas - e recebidas - vistas, ouvidas, lidas - por pessoas em locais específicos. O segundo eixo é a Análise Formal ou Discursiva que tem por objetivo reconhecer a estrutura dos objetos e expressões que circulam nos campos sociais, ou seja, os produtos de ações situadas - que se baseiam em regras, recursos, entre outros - e a expressão das construções simbólicas. O terceiro eixo, Interpretação/Reinterpretação, implica um movimento de construção criativa de possíveis significados, interpretados e reinterpretados pelo pesquisador, com o objetivo de buscar uma explicação interpretativa do que está representado ou do que é dito.

\section{Discussão dos Resultados}

\section{O estudo psicossocial: a quem serve?}

O espaço-tempo da HP entre a Psicologia e o Direito acontece no momento em que o juízo solicita um estudo psicossocial para determinado caso. Na prática, esse estudo só é solicitado quando o juiz e o representante do Ministério Público não conseguem encaminhar a questão com as pessoas envolvidas na lide. Assim, buscam esses juristas, na verdade, um subsídio técnico psicológico, pois reconhecem a capacidade técnica dos profissionais da Psicologia para compreensão do fato ocorrido com a vítima de abuso sexual, por exemplo.

"Nós sabemos que a prova nesses crimes de violência contra a criança, normalmente, é feita com base na palavra de quem sofreu a violência, até porque esse crime ocorre na clandestinidade, às escuras, longe dos olhos de alguém que tenha capacidade de repetir aquilo que aconteceu ou de visualizar e confirmar o que a vítima sofreu (...), nós queremos verificar se o fato foi 'informado' ou 'formado"'. (Juiz)

As palavras do juiz demonstram que o objetivo do estudo psicossocial é a confirmação da existência de abuso sexual. Nesse sentido, quando só há indícios de abuso sexual e as provas nos autos são insuficientes para confirmar a denúncia, o estudo se mostra imprescindível para o convencimento de que o fato realmente aconteceu, na medida em que o fato "informado" é a verificação dos fatos, o "atestado de verdade" de que houve violência, e o fato "formado" é a demonstração de que as informações dadas na Delegacia de Proteção à Criança e ao Adolescente, que, posteriormente, levaram à apresentação da denúncia - esta oferecida pelo Ministério Público -, são inverídicas e fantasiosas.

Isso demonstra que, para os profissionais do Direito, o trabalho do psicólogo consiste na mera verificação dos fatos e na redação do laudo. Silva (2003) afirma que o Poder Judiciário, v.g., entende que o parecer fornecido pelo psicólogo deva funcionar como um "operador da verdade, que irá apenas constar quais fatos e quais argumentos são verdadeiros $e$ quais evidências servem realmente como provas" (p. 177).

Isso, todavia, pode limitar a atuação psicológica, na medida em que se o relatório não contiver as informações de que o juiz necessita, este poderá dispensá-lo, pois, de acordo com a lei processual vigente no Brasil, "o juiz apreciará livremente a prova, atendendo aos fatos e circunstâncias constantes dos autos, ainda que não alegados pelas partes" e, ainda, "o juiz não está adstrito ao laudo pericial, podendo formar a sua convicção com outros elementos ou fatos provados nos autos" (Código de Processo Civil, 1973, arts. 131 e 436, respectivamente).

Normalmente, os psicólogos se vêem obrigados a elaborar laudos conclusivos, segundo Silva (2003), para facilitar e abreviar a decisão judicial. Dessa forma, pode o estudo psicossocial traduzir-se em uma sentença psicológica que é dada, e isso é conseqüência do excesso de processos judiciais - que sobrecarregam o exercício de acusar, defender e julgar - e a dificuldade em ver determinadas questões trazidas ao juízo sob a ótica psicológica (necessitando que as respostas já venham "prontas" do Setor Psicossocial). Segundo a Defensora Pública, o relatório ajuda a condenar ou absolver o réu, in verbis:

“(...) uso como prova, se o relatório não for conclusivo que teve abuso, (...) ou se tiver dúvida, porque ninguém pode ser condenado em caso de dúvida, (...) usaria para alegar essa dúvida (...), eu falo que a psicóloga que condenou ele, porque o relatório dela foi conclusivo (...) ela é muito competente". 
A defensora ainda ressalta que, no caso do processo sob análise, como o parecer foi conclusivo da existência de abuso sexual, ele não foi usado na defesa, na apresentação das alegações finais. Pelo contrário, o parecer serviu para que ela mudasse a sua estratégia de defesa.

\section{“(...) é como se tivesse um DNA, uma prova que deve ser ignorada (...)".}

O Ministério Público, por outro lado, entende que o estudo psicossocial ajuda a compreender a violência desde:

\section{“(...) o minuto que começou ao minuto que acabou, todos} os detalhes, detalhes assim de chocar (...)”.

As palavras da representante do Ministério Público demonstram que os detalhes expressos no estudo psicossocial são importantes para a acusação no processo criminal. Esse é o seu objetivo maior: coletar elementos de prova. Todavia, é possível perceber que existe uma preocupação da promotora em ajudar a vítima a superar o trauma da violência sexual:

\section{“(...) não adianta só a gente resolver o processo: condena} e pronto, e a vítima?"

A fala sugere que o profissional do psicossocial tem a função de receber a vítima logo após o registro da ocorrência policial, como providência preliminar. Nota-se, no entanto, que a promotora desconhece a estrutura do atendimento psicossocial do tribunal e transfere toda a responsabilidade aos psicólogos e assistentes sociais, separando o fato jurídico do fato psicológico. Ademais, vale ressaltar que tal procedimento não está previsto na legislação brasileira como obrigatório, o que demonstra, segundo Amorim (2003), a necessidade de uma troca de "entendimentos fora da lei" entre o juiz, o promotor e a vítima, "uma vez que quando se procura a justiça é porque alguém faltou com a lei, e quando é indicado o atendimento psicológico também está se faltando com a lei e seguindo a subjetividade dos profissionais" (p. 57).

Além disso, percebe-se que a promotora preocupa-se, tãosomente, com o ato de acusar o réu e de defender a vítima. Aplica as suas prerrogativas constitucionais para criar uma máquina de guerra contra o réu, em nome do interesse da criança/vítima. Com seu olhar unilateral, não entende que é preciso enfrentar o problema em toda sua complexidade, buscando opção para, concomitantemente, tratar aqueles que são agredidos e os que agridem, no sentido de que se possa garantir o compromisso em construir uma sociedade que promova a cultura da paz. Maluschke, Bucher-Maluschke e Hermanns (2004) entendem que a punição pelo sistema penal é insuficiente, uma vez que é imprescindível "tratar a vítima e o agressor, visando a uma mudança de mentalidade" (p. 145).

É o que propõem Schnitman e Littlejohn (1999), que, dentro da visão sistêmica novo-paradigmática, o encontro com a família deve ser como um processo de co-criação de contextos que possibilitem a expansão dos territórios afetivos, cognitivos e de ação, orientando-se à criação de possibilidades - subjetivas, intersubjetivas, sociais - para o surgimento de realidades alternativas de expansão da experiência dos participantes.
O estudo psicossocial realiza-se com o objetivo principal de assessorar os magistrados, fornecendo-lhes um relatório com informações que poderão lhe propiciar um entendimento mais amplo da situação na qual as pessoas e, principalmente, as crianças vítimas de abuso sexual estão envolvidas. Assim, o psicólogo ou o assistente social coloca seus conhecimentos à disposição do magistrado, assessora-o em aspectos relevantes para determinadas ações judiciais, coloca nos autos a realidade psicológica dos envolvidos nessas ações que, sem a sua atuação, jamais chegaria ao conhecimento do julgador. Desse modo, o estudo psicossocial é a voz do Setor Psicossocial nos autos.

Mas que voz é essa que o Setor Psicossocial pode oferecer ao juízo, pois, no mais das vezes, o estudo psicossocial transforma-se em um mero elemento informativo no processo, que pode ou não corroborar uma decisão do juiz que favoreça a responsabilização do autor e a proteção da vítima? A par disso, o juízo requer o estudo não para entender a dinâmica relacional e procurar uma decisão mais justa. O objetivo é, unicamente, buscar respostas: com quem a criança deve ficar, se houve abuso sexual, maus-tratos, entre outros.

“(...) só aqueles elementos que ele espera não vão subsidiar uma decisão justa. Ele precisa se ater a essas outras dinâmicas que fazem parte (...), essas outras questões que estão envolvidas numa decisão, para ser uma decisão realmente justa, que não são só fatos que ele tem para usar, mas como que os fatos estão relacionados e se a gente não faz essa avaliação nesse sentido, eu acho que ele fica como se nós fôssemos um terceiro advogado, o advogado da criança (...)” (Psicóloga)

Se o psicólogo é transformado em um terceiro "advogado", advogado da criança, este perde a sua voz nos autos após o envio do estudo psicossocial. Isso porque a resposta dada pelo juízo quando recebe o relatório é o silêncio. Não há um contato prévio do psicólogo com o juiz da causa sob julgamento, o que dificulta substancialmente o estabelecimento de um relacionamento e uma comunicação efetiva entre a Psicologia e o Direito.

“(...) um contato prévio com o juiz antes da solicitação do laudo é fundamental (...) discutir com ele como é que o nosso parecer pode ajudar (...) o que pode oferecer (...) o que cabe a nós (...). Isso nos daria mais segurança na elaboração do parecer”. (Psicóloga)

Percebe-se na fala da psicóloga que os profissionais, que têm como função a realização de estudo psicossocial, apresentam dois olhares ao se depararem com situações de violência intrafamiliar, quais sejam: a) um olhar psicossocial, de atender a criança vítima de abuso sexual e a sua família, com o objetivo de proporcionar um contexto de ajuda, de reflexão, para que possíveis mudanças aconteçam na dinâmica relacional da família vitimizada por esse tipo de crime; e b) um olhar jurídico-policial, de investigação, de verificação dos fatos alegados, exigido pela visão positivista do Direito.

O olhar psicossocial apresenta-se como uma epistemologia sistêmica e se caracteriza pela complexidade, contextualização, causalidades recursivas, instabilidade dos sistemas e 
a inclusão do observador na observação e na construção do conhecimento (Vasconcellos, 2002). Trata-se da objetividade entre parênteses, (Maturana, 1998), em que a pedra de toque da análise da realidade é a sua explicação feita pelo observador. Existem explicações possíveis para tantas realidades que se apresentam, sem, que, necessariamente, uma seja mais verdadeira que a outra. Todas são legítimas.

A visão positivista do Direito entende que o Direito é um sistema de normas, simplesmente, sem indagações sobre sua valorização ética. Assim, como explica Oliveira (2004), "o Direito é tal como se apresenta nas leis vigentes, e nada além disso, (...) e deve ser separado da consideração dos fenômenos sociais" (pp. 135-136). Nesse sentido, Diniz (2005) esclarece que o positivismo jurídico entende que a ciência jurídica deve procurar a base de uma ordem legal, fundamentada na objetividade, previsibilidade, causalidade linear e racionalidade da sua validade legal, "não num princípio metajurídico de moral ou direito natural, mas numa hipótese de trabalho lógico-técnico-jurídica, supondo aquela ordem legal validamente estabelecida" (p. 116).

Essa perspectiva, como afirma Santos (2001), apresenta-se como reguladora da ordem vigente, com o escopo de afastar a tensão entre regulação e emancipação social, priorizando a regulação como forma de conhecimento preponderante e, quem sabe, inquestionável. A busca da realidade única, comprovada pelos fatos da realidade, por meio de uma objetividade em que o observador deve ter a capacidade de usar a racionalidade para separar os fatos e, ao mesmo tempo, apresentar-se como sujeito neutro e imparcial.

Enquanto a atuação do Setor Psicossocial Forense oscila entre esses dois discursos - atender a vítima e a sua família e oferecer informações ao juízo para subsidiar a sua decisão -, os juristas enfatizam o segundo, ou seja, o positivismo jurídico - a confirmação dos fatos por meio da narrativa policial do discurso da vítima.

\section{Quando deve ser realizado?}

O estudo psicossocial mostra-se importante para subsidiar a decisão do juiz e para fazer com que as pessoas envolvidas no litígio compreendam a motivação interna oculta por trás de seus comportamentos e busquem soluções que atendam a sua individualidade e afetividade. Nesse sentido, é preciso conscientizar cada vez mais as autoridades judiciárias e a própria sociedade da necessidade da realização desse estudo, com o estabelecimento de políticas públicas que favoreçam uma política psicossocial, orientada para o atendimento da vítima e do agressor logo após o registro da ocorrência policial na delegacia competente.

No caso de abuso sexual contra crianças, por exemplo, é pacífico o entendimento - para profissionais do Setor Psicossocial Forense e para alguns profissionais do Direito - que o estudo psicossocial deve ser realizado em, pelo menos, três momentos: a) antes da atuação judicial, logo após o registro da ocorrência policial, para que haja encaminhamento a tratamento especializado e aplicação de medidas judiciais adequadas ao caso concreto; b) durante o processo legal, com o objetivo de verificação dos fatos alegados pela vítima e rechaçados pelo réu, a par do acompanhamento psicológico das pessoas envolvidas no conflito; e c) depois do fato judicial, a fim de ajudar as pessoas na compreensão da nova situação apresentada.

“(...) o laudo psicossocial normalmente tem sido apresentado, requerido quando o processo já está em andamento. Esse é um dos equívocos que nós estamos tentando sanar (...) estamos sugerindo que as crianças vitimadas compareçam à delegacia no prazo de 24 horas para que, antes mesmo de o delegado tomar o depoimento da criança, possa um psicólogo ouvir o relato da criança e já emitir um relatório prévio". (Juiz)

O juiz, no seu discurso, demonstra preocupação com o estado físico e emocional da vítima. Para ele, o relatório prévio serviria como embasamento de medidas judiciais:

“(...) mais drásticas, como a prisão, a busca e apreensão, a internação da vítima no sistema de proteção, numa casa de proteção, e tomar medidas mais rápidas que tentem eliminar a principal seqüela desse tipo de crime, que é a seqüela emocional (...)".

Todavia, a despeito de o discurso do juiz apresentar-se como inovador, uma vez que propõe um atendimento psicossocial da vítima antes da instauração do inquérito policial e da propositura da ação penal, as suas palavras demonstram que a utilidade do relatório apresentado no primeiro momento teria como ponto nodal a utilização dos instrumentos oferecidos pela Psicologia para reforçar o controle social, "a natureza repressora do Direito, onde os conflitos permaneceriam sem solução, mas submetidos à ordem jurídica, em detrimento da observância dos direitos fundamentais dos indivíduos ditados pela Constituição da República Federativa do Brasil de 1988" (Verani, 1994, p. 14).

Nessa visão, mais uma vez a Psicologia seria utilizada como uma ciência que, segundo Pereira (2003), reforça o poder do Direito - o poder de sanção, de julgar o que é certo ou errado, regulando as relações do homem na sociedade. O estudo psicossocial prévio apresentar-se-ia com a mesma função do segundo momento, isto é: desvendar os fatos ocultos, o segredo familiar incestuoso para um intermediário, o psicólogo, que deverá apresentar um laudo que determina os culpados e os inocentes, eximindo, assim, o juiz da responsabilidade de pensar o problema que vem solucionado às suas mãos.

Não se trata, aqui, de afastar a idéia da necessidade de um atendimento prévio da vítima e também do suposto agressor, no momento em que há o registro da ocorrência policial. O que se deseja é uma práxis de interface entre a Psicologia e o Direito, em que aquela procura entender o comportamento humano, enquanto este se preocupa com a tomada de decisões justas e adequadas a cada caso, com o objetivo de estabelecer uma convivência comunitária voltada para a promoção da paz. Nesse sentido, faz-se mister que - mesmo antes da propositura da ação penal - o juiz, o promotor, o delegado de polícia e o psicólogo estejam engajados em um mesmo projeto, que exige um estabelecimento de um diálogo pré-judicial entre esses profissionais.

Para que isso se torne exequíivel, seria necessária a criação de varas especiais para julgar esse tipo de crime, sendo que a localização de tais varas não seria em um edifício com outras 
tantas varas judiciais com diversas competências, mas, sim, na própria Delegacia de Proteção à Criança e ao Adolescente. Isso proporcionaria a aproximação desses profissionais, um maior conhecimento e respeito da atividade de cada um, e todos teriam voz para elaborar estratégias de atuação conjunta.

Souza (1990) defende que o "Direito necessita trabalhar não só com a lógica da norma, mas também com a lógica empírica das causas e efeitos sociais da norma" (p. 125). Para isso, é mister afastar a idéia de que o Direito é uma ciência centrada basicamente na interpretação técnica de textos legais, o que ocasiona o afastamento dos juristas das Ciências Humanas e Sociais. Esse fato contribui, segundo Brito (1993), para a imagem passiva que se forma a respeito do juiz, visto como "mero aplicador da lei, ocultando-se a importância do elemento humano em toda a atividade judicial"' (p. 84).

Assim, no que respeita ao segundo momento da realização do estudo psicossocial, a criação de varas especiais, como já defendido, afastaria, de certa maneira, a malograda sentença psicológica a que o Setor Psicossocial Forense se vê obrigado a "proferir" por exigência judicial. Isso porque o trabalho integrado dos profissionais do Direito e da Psicologia promoveria uma decisão coerente, justa, exequiível e partiria de uma ação reflexiva, em que o elemento humano se sobreporia às exigências do formalismo jurídico.

Os arts. 10 e 11 da Lei de Execução Penal, Lei no 7.210/84, preceituam, in verbis:

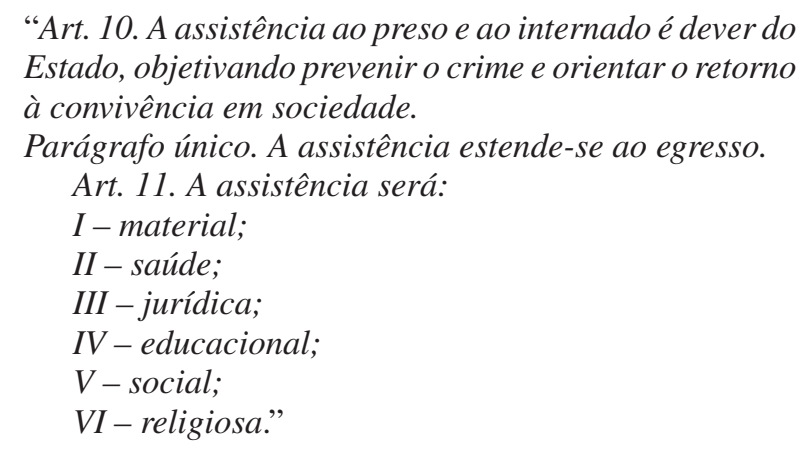

Como se pode notar, a Lei de Execução Penal não traz, no seu texto, nenhum inciso que contempla o atendimento psicológico do apenado, seja na instituição penitenciária, seja em outro local especializado. O que essa lei determina é o exame criminológico para a classificação do grau de periculosidade do preso e elaboração do programa de cumprimento da pena a que será submetido o condenado, este elaborado pela Comissão Técnica de Classificação.

Nesse sentido, o terceiro momento do estudo psicossocial apresentar-se-ia com uma dificuldade maior, qual seja: a ausência de previsão legal para o atendimento do agressor e da vítima após a prestação da tutela jurisdicional. Vale lembrar que essa ausência de previsão legal também está presente no primeiro momento, porém, a exeqüibilidade dessa proposta é mais concreta, na medida em que ela se apresenta como um procedimento pré-judicial. No entanto, nada impede que políticas públicas sejam elaboradas para alcançar esse objetivo. O poder público tem a opção de criar núcleos de atendimento psicossocial dentro das penitenciárias, para os presos que ainda cumprem pena, e fora delas, para aqueles que já alcançaram o livramento condicional. Para as vítimas, nada há de impedimento legal no estabelecimento de convênios com consultórios particulares de Psicologia ou a criação de uma sessão especializada no Setor Psicossocial Forense para o atendimento desses casos. Tudo isso corrobora a idéia de que o encaminhamento jurídico, muitas vezes, não é suficiente para garantir o fim da violência. O desafio é reformar o pensamento com vistas a transformar a ação, pois, para responder a esses desafios que se impõem tanto ao Direito quanto à Psicologia, faz-se necessária a ligação dessas duas áreas que se encontram dissociadas.

\section{O que subsidia o processo: o laudo ou o relatório?}

As expectativas do Direito em relação às possibilidades e ao alcance do trabalho do Setor Psicossocial Forense são viáveis. No entanto, há uma grande diversidade em relação ao que é solicitado pelo juízo e a prática desenvolvida pelos psicólogos e assistentes sociais. Isso porque o Direito exige respostas imediatas e definitivas, o que vai de encontro à proposta do Setor Psicossocial, que tem como norte não só a elaboração de um estudo psicológico, mas também a intervenção terapêutica adequada às partes envolvidas em um conflito judicial.

O juízo, ao verificar a necessidade de comprovação de uma denúncia de abuso sexual, por exemplo, encaminha a vítima ao Setor Psicossocial, para que o psicólogo elabore um laudo acerca da existência ou não de violência sexual. Por sua vez, o psicólogo responde à pergunta judicial com um relatório. Mas qual é a diferença entre esses dois documentos? Segundo Aurélio (1999), o laudo é uma peça escrita, fundamentada, na qual os peritos expõem as observações e estudos que fizeram e registram as conclusões da perícia. O relatório, por sua vez, é uma narração ou descrição verbal ou escrita ordenada, e mais ou menos minuciosa, daquilo que se viu, ouviu ou observou.

O laudo, para Silva (2003), é um documento final feito pelo perito, "no qual resume quanto pôde observar durante as diligências" (p. 169). Assim, esse documento pode ser entendido sob dois aspectos: a) como a materialização do trabalho pericial realizado pelo perito; e b) como a própria prova pericial, sob o aspecto técnico, "que servirá para suprir as insuficiências do magistrado no que se refere a conhecimentos técnicos ou científicos, propiciando a certeza jurídica quanto à matéria fática" (p. 169).

Por sua vez, o relatório apresenta-se com um olhar na dinâmica relacional da família envolvida em um conflito judicial, é uma apresentação descritiva e/ou interpretativa "acerca de situações ou estados psicológicos e suas determinações históricas, sociais, políticas e culturais" (Conselho Federal de Psicologia, Resolução no 17/2002). Busca-se, segundo Silva (2003), uma avaliação psicológica, por meio de subsídios fornecidos por um instrumental técnico (entrevistas, dinâmicas, testes, observação) e de um referencial técnico-filosófico e científico.

O juízo, ao requerer a realização de um laudo psicossocial, entende a ação, o ato do psicólogo como uma perícia, que é algo que diagnostica, que investiga. A sua perspectiva é de investigação, mas exige uma resposta para uma determinada situação-problema. A psicóloga, no entanto, denomina o que ela 
faz de relatório, que visa, inicialmente, à compreensão do problema e, em segundo lugar, à investigação solicitada pelo juízo.

“(...) o relatório te auxilia, (...), me auxilia dando a idéia de que aquele fato realmente aconteceu, não é ilusão, não é uma história inventada, me auxilia na desiometria da pena, porque o relatório é que vai me dizer quais as seqüelas que a vítima tem, e uma das circunstâncias que são consideradas para fixação da pena é dada no artigo 59 do Código Penal”. (Juiz)

“(...) aqui a gente atua de forma diferenciada de como a gente atua no consultório. Você é um pouco mais objetiva, mais diretiva. Você investiga ao mesmo tempo em que você procura encaixar as informações num contexto relacional, das emoções dos indivíduos, da história de vida, você faz todo um trabalho psicológico mais bem direcionado”. (Psicóloga)

“(...) o laudo é imprescindível para o processo. Quando tem avaliação psicológica isso daí facilita (...) para todo mundo, para você se convencer do que realmente aconteceu”. (Defensora)

“(...) O principal motivo de solicitar o laudo psicossocial é buscar, primeiro, elementos para uma eventual propositura de uma ação penal contra o infrator (...) $e$, segundo, dar um auxílio, um tratamento à vítima da violência”. (Promotora)

Tudo isso denota que há uma zona de conflito entre o que é solicitado e o que é apresentado, que fica clara na utilização do estudo psicossocial, pois o juízo o aplica numa via de mão única, ou seja, para prover as demandas judiciais em detrimento das psicológicas. O laudo, nessa perspectiva, é utilizado como um instrumento para corroborar a decisão judicial - absolver ou condenar o réu.

A promotora, na última citação, manifesta certa preocupação com a vítima, na medida em que entende que ela precisa de acompanhamento psicológico. Isso pode ser considerado um avanço, na medida em que essa jurista reconhece que o Direito, ou grande parte dele, está impregnado de componentes psicológicos (Brito, 1999). Entretanto, Cesca (2004) lembra que "de nada adianta encaminhar para tratamento $e$ programas se não é dada uma atenção especial às famílias, um 'empurrãozinho' para que as coisas aconteçam” (p. 3).

“(...) então o relatório vai dizendo de uma dinâmica relacional quando, muitas vezes, o que o juiz quer ouvir não é sobre a dinâmica, mas sim com quem a criança vai ficar, aí você imagina que talvez você esteja dando mais elementos do que ele espera (...). Em alguns momentos, eu tenho a sensação de que só aqueles elementos que ele espera não vão subsidiar uma decisão justa. Ele precisa se ater a essas outras dinâmicas que fazem parte (...). Essas outras questões que estão envolvidas numa decisão”. (Psicóloga)

A colaboração da Psicologia com o propósito de obtenção de eficácia jurídica se revela, inicialmente, com a elaboração de um relatório psicossocial, pois o fenômeno da violência é complexo e deve ser encarado pelos profissionais que lidam com ela no dia a dia como tal. Enfrentar a violência só com medidas punitivas é atirar no próprio pé. A par de medidas punitivas, se realmente necessárias, devem ser criadas medidas de apoio à vítima, à sua família e ao agressor. A assistência, social, psicológica e jurídica, é necessária para a recomposição da família após a violência sofrida.

A observação da psicóloga revela que a decisão judicial poderá não ser justa, se os juristas não compreenderem a dimensão sistêmica da violência. O envio de um relatório - e não de um laudo - é um grito "silencioso" do Setor Psicossocial pela maior integração entre o Direito e a Psicologia. É uma mensagem de alerta da existência de um impasse a ser transplantado e da necessidade de se construir uma relação mais consistente entre essas áreas, pois essa relação ainda se dá de forma estremecida e o lugar do psicólogo na instituição judiciária ainda está por se configurar (Cesca, 2004).

A solicitação de um estudo psicossocial deve possibilitar o encontro do psicólogo com o solicitante, a fim de promover uma relação dialógica acerca do problema a ser compreendido e investigado. Dessa forma, um novo olhar será construído e parcerias serão estabelecidas e fortalecidas, o que desencadeará novas possibilidades de trabalho e a transposição de inúmeros impasses entre essas áreas de conhecimento, estes fixados pela separação dos saberes.

\section{Considerações Finais}

A realidade de distanciamento, de alheamento do juiz diante das questões que lhe são colocadas precisa ser desconstruída. Não se trata de retirar-lhe a autoridade, mas, sim, fazer com que essa autoridade seja ampliada, isto é, sua autoridade deve contemplar a realidade das pessoas que julga. A desconstrução da visão desfocada, distante da realidade concreta, depende de uma relação de reciprocidade, de mutualidade, de co-propriedade, de inter-ação, que irá tornar possível o diálogo entre os interessados.

No que concerne ao estudo psicossocial, promover a interação depende, basicamente, de mudança de atitude perante a sua utilização. $\mathrm{O}$ juiz, preocupado em julgar, em proferir uma sentença, busca no relatório um ponto, um aspecto para complementar a sua decisão. Só que o relatório tem uma série de detalhamentos, que são de ordem dinâmica, que quando o juiz os despreza, deixa de acompanhar os resultados posteriores à sentença. A violência não é somente um fenômeno do micro, do processo; é um fenômeno de conjugação de micro e macro. Assim, deve-se questionar a concretude daquela "situação de vida", na medida em que o seu desvendamento pode ser relevante para a efetividade da decisão.

Nesse sentido, ampliar a realidade requer, também, que haja a inter-comunicação ao final da sentença, isto é, a comunicação não pode parar na sentença. Mas o juiz não pode falar. Seu papel institucional é apolítico. Por que o Poder Judiciário não pode ter uma posição política em relação à execução das sentenças que profere? Quem exerce esse papel? A falta de inter-ação se dá igualmente entre a Magistratura e o Ministério Público. Se esses atores jurídicos tivessem maior diálogo, eles obrigariam o Estado a fazer o seu papel, isto é, oferecer condições de vida digna à população. Isso 
poderia minimizar o ciclo recursivo de violência intrafamiliar enfrentado diuturnamente pelos tribunais e promoveria uma justiça cidadã, voltada para a camada da população mais necessitada.

\section{Referências}

Amorim, E. P. (2003). O processo de mediação com famílias em conflito judicial:_negociando desacordos e construindo possibilidades. Dissertação de Mestrado, Instituto de Psicologia, Universidade de Brasília, Brasília.

Aurélio, B. de H. F. (1999). Novo aurélio - século xxi: o dicionário da língua portuguesa. Rio de Janeiro: Nova Fronteira.

Brito, L. M. T. de (1993). Separando: um estudo sobre a atuação do psicólogo nas varas de família. Rio de Janeiro: RelumeDumará/UERJ.

Brito, L. M. T. (1999). Temas de psicologia jurídica. Rio de Janeiro: Relume Dumará

Brito, L., Ayres, L. \& Amendola, M. (2006). A escuta de crianças no sistema judicial. Psicologia \& Sociedade, 18 (3), 68-73.

Bucher, J. S. N. F. (1992). Lei, transgressões, famílias e instituições: elementos para uma reflexão sistêmica. Psicologia: Teoria e Pesquisa, 8 (suplemento), 475-483.

Cesca, T. B. (2004). O papel do psicólogo na violência intrafamiliar: possíveis articulações. Psicologia Social [on line]. Set/dez. 2004, vol. 16, no 3 [citado 22 fevereiro 2006], p. 41-46. Retirado em 14/01/2006 de http://www.scielo.br/scielo.php?Script=sci arttest\&pid $=$ so102-71822004000300006\&luj $=p+\& n r m=i s o$. ISSN01027182.

Código de Processo Civil. Lei no 5.869, de 11 de janeiro de 1973.

Conselho Federal de Psicologia, Resolução no 17/2002.

Constituição da República Federativa do Brasil, promulgada em 05 de outubro de 1988.

Corsi, J. (1999). Violencia familiar: una mirada interdisciplinaria sobre un grave problema social. ( $3^{\mathrm{a}} \mathrm{ed}$.). Buenos Aires: Paidós.

Costa, L. F. \& Santos, V. A. (2004). Família e violência sexual contra crianças: o papel da justiça na construção e reconstrução de significados. Psicologia. Teoria, investigação e prática, 9 (1), 47-63.

Costa, L. F., Penso, M. A. \& Almeida, T. M. C. (2005). O grupo multifamiliar como um método de intervenção em situações de abuso sexual infantil. Psicologia USP, 16 (4), 121-146.

Costa, L. F., Penso, M. A. \& Almeida, T. M. C. (2006). Nos bastidores da pesquisa: Dificuldades no procedimento metodológico em situações-limite. Psico, 37 (2), 175-181.

Diniz, M. H. (2005). Compêndio de introdução à ciência do direito. (17 ed. à luz da Lei n. 10.406/02). São Paulo: Saraiva.

González Rey, F. (2002). Pesquisa qualitativa em psicologia: caminhos e desafios. (M. A. F. Silva, Trad.). São Paulo: Thomson. (Trabalho original publicado em 2000)

Lima, H. G. D. (2003). Apresentação. Em H. G. D. Lima (coord.), Construindo caminhos para a intervenção psicossocial no contexto da Justiça (pp. 15-18). Brasília: TJDFT.

Maluschke, G, Bucher-Maluschke, J. \& Hermanns, K. (2004). Direitos humanos e violência: desafios da ciência e da prática. Fortaleza: Fundação Konrad Adenaeur.
Maturana, H. (1998). Emoções e linguagem na educação e na política. (J. F. C. Fortes, Trad.) Belo Horizonte: UFMG (Trabalho original publicado em 1998).

Morin, E. (1990). Introdução ao pensamento complexo. (D. Mattos, Trad.) Lisboa: Instituto Piaget. (Original publicado em 1990).

Nichols, M. P. \& Schwartz, R.C. (2007). Terapia Familiar: Conceitos e Métodos. (M. A. V. Veronese, Trad.) ( $7^{\mathrm{a}}$ ed.) Porto Alegre: Artmed.

Oliveira, J. M. L. L. de (2004). Introdução ao direito. Rio de Janeiro: Lumen Juris.

Penso, M. A. \& Sudbrack, M. F. O. (2004). Envolvimento em atos infracionais e com drogas como possibilidade para lidar com o papel do filho parental. Psicologia USP, 15 (3) 29-54.

Pereira, R. C. (2003). A primeira lei é uma lei de direito de família: a lei do pai e os fundamentos da lei. Em G. C. Groeninga \& R. C. Pereira (Org.), Direito de família e psicanálise: rumo a uma nova epistemologia (pp. 55-88). Rio de Janeiro: Imago.

Santos, B. de S. (2000). A crítica da razão indolente: contra o desperdício da experiência ( $3^{\mathrm{a}}$ ed.). São Paulo: Cortez.

Santos, B. de S. (2001). Pela mão de Alice: o social e o político na pós-modernidade ( $8^{\mathrm{a}}$ ed.). São Paulo: Cortez.

Schnitman, D. F. \& Littlejohn, S. (1999). Novos paradigmas em mediação. (J. H. Rodrigues \& M. Domingues, Trads.). Porto Alegre: Artes Médicas. (Original publicado em 1999).

Silva, A. J. (2000). Curso de direito constitucional positivo. (17 $\mathrm{ed}$.). São Paulo: Malheiros Editores.

Silva, D. M. P. (2003). Psicologia jurídica no processo civil brasileiro: a interface da psicologia com direitos nas questões de família e infância. São Paulo: Casa do Psicólogo.

Soares, B. M. (1999). Mulheres invisiveis: violência conjugal e as novas políticas de segurança. Rio de Janeiro: Civilização Brasileira.

Sousa Júnior, J. G. de (2002). Sociologia jurídica: condições sociais e possibilidades teóricas. Porto Alegre: Sergio Antonio Fabris Editor.

Souza, A. C. (1990). O método científico e o direito - positivismo $\mathrm{x}$ dialética. Revista da Associação dos Juízes do Rio Grande do Sul, 1 (1), 23-45.

Sudbrack, M. F. O. (1992). Da falta do pai à busca da lei - o significado da passagem ao ato delinqüente no contexto familiar e institucional. Psicologia: Teoria e Pesquisa, 8 (suplemento), 447-457.

Thompson, J. B. (2000). Ideologia e cultura moderna: teoria social crítica na era dos meios de comunicação de massa. (Grupo de Estudos sobre Ideologia, Comunicação e Representações Sociais da Pós-graduação do Instituto de Psicologia da PUCRS, Trads., $5^{\mathrm{a}}$ ed.). Petrópolis: Vozes. (Original publicado em 1995).

Vasconcellos, M. J. E. de (2002). Pensamento sistêmico: o novo paradigma da ciência. Campinas: Papirus.

Verani, S.S. (1994). Alianças para a liberdade. Em L. M. T. Brito (Org.), Psicologia e instituições de direito: a prática em questão (pp. 5-9). Rio de Janeiro: CRP/RJ, Comunicarte.

Recebido em 15.03.2007

Primeira decisão editorial em 29.06.2007

Versão final em 20.07.2007

Aceito em 16.02.2008 